\title{
Las lecciones de Xavier Albó
}

\author{
Irma Alicia Velásquez Nimatuj \\ Antropóloga Maya-K'iche'
}

Compañeras y compañeros, hermanas y hermanos, tengan todos muy buenas tardes. En el marco del otorgamiento del premio Martin Diskin Memorial Lectureship que la Asociación de Estudios Latinoamericanos (LASA por sus siglas en inglés) concede anualmente a quienes han dado su vida a la lucha por la equidad y la justicia social de los pueblos de América Latina, deseo agradecerle al comité organizador por invitarme a compartir con ustedes unas palabras sobre la vida, el legado y la lucha de Xavier Albó, quien este año está recibiendo esta merecida distinción.

Siendo parte de apenas un pequeño puñado de mujeres indígenas de Latinoamérica que hemos tenido el privilegio de formarnos y llegar por múltiples caminos a la universidad, en uno u otro momento de nuestras vidas nos hemos acercado a la producción académica, a las reflexiones, pero sobre todo al trabajo ejemplar, sincero y transparente de acompañamiento político que Xavier fue construyendo lentamente con los 36 pueblos indígenas que comparten el territorio de Bolivia, especialmente con los pueblos aymara, quechua y guaraní. Por eso, su trabajo ha traspasado las puertas de la academia y de una u otra manera ha impactado en otros pueblos originarios, porque en el fondo las opresiones y los deseos profundos que mantenemos por lograr la liberación económica y enterrar el colonialismo atraviesa a la mayoría de los habitantes.

Xavier forma parte de esa generación de miembros de La Compañía de Jesús que, como Ricardo Falla, Segundo Montes, Ignacio Martín-Baró, Juan Ramón Moreno Pardo, Ignacio Ellacuría, César Jeréz García, Claudio Pou, Luis 
Alegre, Juan Hernández Pico y otros, han trabajado hombro con hombro al lado de los pueblos a los que decidieron incorporarse y servir, y que coherentes con sus votos de acompañar a los de abajo se han entregado, a través de la vida cotidiana primero, a comprender; posteriormente a aprender $y$, finalmente, a asumir las complejas resistencias de los pueblos indígenas de las Américas por los medios que los pueblos han optado y decidido. $Y$ lo hicieron a través de entregar su trabajo día a día, mes a mes y año tras año hasta construir el legado que hoy es un modelo y una referencia para quienes luchan por usar la academia, en concreto las ciencias sociales, como un arma política que sirva para transformar las desiguales relaciones de poder junto a las complejas opresiones coloniales que aún arrastramos y reproducimos.

Es desde esa perspectiva que intento acercarme para entender la vida de Xavier Albó, a quien hoy celebramos. Una vida que sin estar ajena a las contradicciones por los privilegios inherentes a los que tuvo acceso y con los que nació aquí en Cataluña, nos muestra con el paso de los años que él no solo reconoció, sino sobre todo utilizó el privilegio de ser un hombre blanco, europeo, formado a mitad del siglo pasado en medio de las cenizas, las heridas y las enseñanzas que dejó la Segunda Guerra Mundial en Europa, y con esas herramientas decidió trasladarse en 1951 a Bolivia, uno de los países de América cuya organicidad estaba marcada por poblaciones indígenas que analizaban su pasado estando parados en su presente para soñar y construir un futuro estratégico. En efecto, en permanente entereza habían venido los pueblos originarios de Bolivia construyendo su historia y su memoria del antes y de ese presente, alrededor de las múltiples resistencias que hicieron temblar a las élites durante la época colonial, liberal y moderna al sitiarles una y otra vez su centro de poder político.

Élites reproductoras del miedo colonial, que como único escape buscaron instituir un régimen sanguinario, inhumanamente racista y excluyente que basaba su poder y la acumulación de la riqueza a través de extender las líneas de la colonialidad que son precisamente las que Xavier encuentra a su llegada a Bolivia y que le impactan profundamente. Estoy convencida que fue esa realidad existencialmente vergonzosa en contra de los pueblos indígenas de Bolivia -que eran los generadores del capital con su fuerza de trabajo- la que transformaría y definiría la vida y el trabajo que decidió realizar Xavier. Para ese entonces, como se ha documentado, las mujeres y los hombres indígenas de Bolivia eran rociados con insecticidas antes de ingresar a las oficinas públicas. 
Esa amalgama de opresiones, saqueos y larga explotación que se ejecutaba en el marco de dictaduras militares y autoritarismo, que se ejercía frente a sus ojos y en contra de los pueblos milenarios que no solo eran la mayoría de la población, sino que con rebeldía histórica se negaban a vivir de rodillas, fueron realmente los factores que crearon la conciencia social de Xavier. Ese darse cuenta del desprecio y la burla con que se recibía a las mujeres y hombres indígenas que se comunicaban en sus idiomas ancestrales fue lo que, sin temor a equivocarme, desembocó en que Xavier decidiera trabajar en el campo de la lingüística y, desde allí, no solo estudiar los idiomas, sus gramáticas, la riqueza estructural y simbólica que poseen como lenguas vivas, sino además, trabajar en la construcción de políticas públicas para que las poblaciones indígenas pudieran, además de tener documentos sobre sus idiomas, crear instituciones o transformar instituciones que ya existían para que ellas y ellos ejercieran el derecho a educarse en sus idiomas maternos, de sentirse orgullosos de hablar en los espacios en donde se desenvolvían con la simbología propia de sus ancestros y en los que se sentían con comodidad. Se trataba de ejercer derechos que todo ser humano tiene, en cualquier lugar y en cualquier espacio.

Es evidente que el amplio legado de estudios y análisis materializados en libros, artículos especializados y de prensa que Xavier ha producido de manera personal o en colectividad, son una muestra de cómo las plataformas académicas deciden no ponerse al servicio exclusivamente de carreras personales, sino al servicio de las luchas colectivas y políticas de los pueblos, usando los espacios que el contexto permite para educar, analizar, denunciar y demandar, desde tribunas académicas, a las elites, la burocracia estatal, las clases medias y a la misma academia, sobre las prioridades que deben atenderse pero también sobre las miserias que denigran a otros seres humanos y que por principio hay que combatir.

La vida de Xavier está llena de pasión y de esa sencillez que lo rebalsa y contagia. Por eso, lo realizado hasta el día de hoy lo ha hecho desde ese ser humano que ha buscado, por todas las formas posibles, quitarse los lentes del privilegio, salir de su burbuja y de su zona de confort para ver y asumir en condiciones de igualdad el camino de quienes siendo también seres humanos, están ubicados en el último nivel de una jerarquía racial (creada y sostenida por pequeñas élites blancas) que les niega hasta el derecho de sentir dignidad.

En ese proceso ubico la fundación del Centro de Investigaciones y Promoción del Campesinado, CIPCA, que fue fundado en 1970 por Xavier Albó, Luís Alegre y Francisco Javier Santiago como un espacio en donde los sectores 
campesinos y los 36 pueblos indígenas pudieran construir sus caminos de emancipación a través de tener sus propios espacios de discusión, formación y creación. Espacios claves y necesarios para todos los colectivos que han buscado que la descolonización no sea solo un discurso, sino intentos reales y a veces contradictorios para construir alternativas propias y no impuestas. Pienso, entonces, en los pueblos mayas de Guatemala y nuestro sueño de tener nuestra propia universidad maya, nuestro propio centro de formación que sirva para lo que deseamos y necesitamos, que es formar a nuevas generaciones críticas de jóvenes indígenas, pero que por múltiples impedimentos internos y externos nunca lo hemos logrado, a pesar que, al igual que en Bolivia, somos la mayoría del país.

CIPCA rememora parte de lo que los mayas de Guatemala no hemos logrado y que sigue siendo clave, porque como Xavier mostró, no basta hablar por los indígenas, lo clave fue y sigue siendo crear espacios para que los propios pueblos se liberen a través de la formación y los centros de pensamiento. Porque son esos espacios de reunión y reflexión los que permiten condiciones para albergar utopías a cualquier generación.

Me compartía mi colega Lucia D’ Emilio, quien trabajó y conoce desde décadas atrás a Xavier, que una de esas utopías que las poblaciones indígenas de Bolivia mantenían, y que Xavier entendió con facilidad, era el deseo válido y profundo de ser gobernados por ellos y ellas mismas y que él apoyó, y en efecto vivió para ser testigo de cómo las palabras de Julián Apaza -Túpac Katari- de 1781, seguían resonando en la memoria social de los indígenas, cual eco histórico, que les recordaba: "iYo moriré pero volveré y seré millones!" En ese proceso, el Xavier acompañante, el colega y el hermano, fue testigo de cómo esas luchas se fueron gestando desde las cotidianidades. En ese marco mencionaré dos ejemplos, el primero, las luchas de 1977 lideradas por valientes mujeres, una de ellas Domitila Chungara, aquella lideresa que en 1975, en México, en ocasión de la celebración del Año Internacional de la Mujer impulsado por Naciones Unidas le recordó, a través de su vida, a las mujeres que lideraban el evento y al mundo entero, que no todas las mujeres somos iguales porque no todas enfrentamos las mismas opresiones. Entonces, Xavier no tuvo empacho en unirse a la resistencia de esas mujeres contra el régimen de Hugo Banzer Suárez. Gran ejemplo de cómo esa lucha de mujeres, de cómo la fuerza de mujeres como Domitila terminaron contagiando a Xavier.

Y el segundo ejemplo, es Xavier acompañando al dirigente Evo Morales hasta ganar la presidencia de Bolivia en 2005. Sin embargo, su compromiso nunca le ha hecho cerrar los ojos, al contrario, parte de esa conexión que 
mantiene permanentemente con el pueblo y las bases se la ha trasladado de manera crítica al hoy Presidente Evo para que evite repetir la historia de agravios que fueron los que lo llevaron a la presidencia.

Entonces, ¿qué he aprendido de lo escrito y vivido por Xavier? Bien, que el trabajo académico es también un trabajo político y que ese es un principio al que no debemos renunciar sino usar estratégicamente. Segundo, que todo trabajo con las comunidades es de largo alcance, o sea, es un compromiso para toda la vida y, aunque se puede, no debe ser temporal, por una necesidad económica, o por escribir una disertación doctoral. Tercero, que deben acompañarse y asumirse las luchas que las comunidades prioricen, no las que le interesan al investigador. En este caso, Xavier nos enseñó su capacidad de realizar alianzas con otros académicos para producir documentos que los pueblos indígenas de Bolivia necesitaban alrededor de su lucha por la tierra o por defender los idiomas originarios. Cuarto, despojarse del colonialismo asumiendo y reconociendo que las comunidades están llenas de actores y actoras en medio de sus propios medios y condiciones y no son seres viviendo en perpetua opresión, porque solo así se pueden construir lazos colectivamente. Quinto, a las comunidades no se llega a dirigir, se llega a aprender, y ésta es quizá una de sus enseñanzas claves para quienes se consideran "vanguardia", a ellas y ellos Xavier les está diciendo que no llegarán lejos, porque tarde o temprano serán evidenciados, denunciados y sacados de esos espacios. La historia actual ya no tiene cabida para los "iluminados externos" que buscan un protagonismo individual. Y sexto, con voluntad, se pueden convertir y usar los instrumentos e instituciones existentes en espacios para generar resistencias y buscar la liberación de los que viven en opresión. La creatividad no tiene límites cuando de romper cadenas se trata.

Finalmente, quiero concluir expresando mi felicitación a Xavier por este merecido reconocimiento y, al mismo tiempo, compartiendo con ustedes una profunda decepción por el rol que algunos miembros de las generaciones actuales de jesuitas han asumido al unirse a los sectores conservadores de los países en donde sirven y que ahora contribuyen a que el colonialismo siga reproduciéndose en abundancia para fortalecer los privilegios de las élites. Y aunque no se trata de romantizar el trabajo de Xavier, de la antropología o de las ciencias sociales, sí hay que solicitar que quienes hoy están en espacios de poder los asuman y los usen como un arma política que pueda impactar en estos momentos de incertidumbre y destrucción por los que atraviesa la humanidad. Y aunque lamento la ausencia física de Xavier, quisiera también hacer un llamado a LASA y a estos reconocimientos, porque celebrar la vida, 
celebrar los lazos y el legado, no debe de hacerse, y presto aquí las palabras de Ricardo Falla, "al atardecer de la vida", sino deben de realizarse antes, porque deberíamos de tener un margen necesario para que las generaciones de niños y de jóvenes puedan tener la oportunidad de nutrirse de seres humanos que, como Xavier, nos han enseñado que no basta con soñar, sino que lo más hermoso de la vida es, sobre todo, construir. Muchas gracias.

Barcelona, mayo de 2018

\section{$((c))$ EY}

This journal is published by the University Library System of the ULIS D-forke University of Pittsburgh as part of its D-Scribe Digital Publishing Program, and is cosponsored by the University of Pittsburgh Press. 